\title{
Perfiles de la producción textil en un espacio regional: Conchucos, Ancash, Perú entre 1593 y $1876^{*}$
}

\author{
Magdalena Chocano*
}

\begin{abstract}
RESUMEN
Existe una gran cantidad de datos que sugieren que el corregimiento de Conchucos tuvo una significativa producción textil. La sistematización de esa información nos ha permitido trazar una geografía de la economía textil de ese territorio que destaca las zonas donde se desarrollaron los obrajes. Por otra parte, aunque la carencia de series para la producción textil de Conchucos no permite realizar un estudio de ese sector equiparable a los realizados para Huamanga o el Cusco, la información demográfica existente para aquella circunscripción, permite trazar un panorama de la evolución a largo plazo de su economía textil hasta su escisión en provincias ya en la época republicana. A través de ese análisis se puede percibir la distribución étnica y sexual del trabajo en el sector textil, y esclarecer algunos elementos de cambio económico que afectaron a ese territorio.
\end{abstract}

Palabras clave: producción textil, manufactura, obrajes, demografía, trabajo textil.

Clasificación JEL: N66, N46, N86

\section{Profiles of Textile Production in a Regional Space: Conchucos, Ancash, Perú, between 1593 and 1876}

\begin{abstract}
There is a good deal of data to suggest that the corregimiento of Conchucos was a significant textile production center. The systematization of this data has allowed us to map out the geography of the textile economy in the area, highlighting those zones where the work was carried out. On the other hand, although the lack of series for the textile production of Conchucos precludes a study of this sector that is comparable with that of Huamanga or Cusco, the available demographic information for the corregimiento allows the long-term evolution of its textile economy to be traced through to the eventual division into provinces during the Republican era. This analysis allows the ethnic and gender distribution of work in the textile sector to be discerned, while elucidating some of the elements of economic change that affected this territory.
\end{abstract}

Keywords: textile production; manufacturing; obrajes; demographics; textile work.

JEL Codes: N66, N46, N86

\footnotetext{
* Una primera versión de este trabajo se presentó en el $1^{\circ}$ Congreso de la Asociación Peruana de Historia Económica, Ayacucho, agosto de 2013.

** Doctora en Historia, Universidad del Estado de Nueva York, Stony Brook. Profesora de la Escuela Profesional de Historia, Universidad Nacional Federico Villarreal.
} 


\section{INTRODUCCIÓN}

Son muchos los indicios que apuntan a la importancia de la producción textil en el territorio que constituyó el corregimiento de Conchucos, aunque se trata de datos dispersos. No es posible todavía un estudio de series de producción textil como los realizados para Huamanga, el Cusco y Quito ${ }^{1}$. Aun así intentamos aquí trazar un panorama de la economía textil del corregimiento y su derrotero al escindirse en provincias republicanas. Partimos de tres momentos en que es posible obtener datos generales, sea sobre la población que habitaba los centros reconocidos como obrajes o chorrillos (talleres de elaboración de tejidos), sea sobre la población ocupada en labores textiles. En el primer caso entran la visita realizada por el arzobispo fray Toribio de Mogrovejo en 1593-1594 en las doctrinas o parroquias de dicho corregimiento, y los padrones elaborados por los curas de las mismas en 1774, con los que hemos formado una estadística general por asentamientos que constituye la base para algunas afirmaciones que hacemos aquí. En el segundo caso, la base la forman los datos recopilados en el censo de $1876^{2}$.

Algunas observaciones preliminares sobre el espacio son necesarias para ubicar mejor el alcance de nuestras propuestas. El corregimiento de Conchucos, integrado por quince doctrinas o parroquias, pasó a conformar el partido de Conchucos a raíz de la implantación de las intendencias. Ya organizada la república fue dividido en dos partidos o provincias: Huari o Conchucos Bajo y Conchucos Alto o Pallasca, y quedó integrado en el departamento de Huaylas. Hacia 1876 el territorio del antiguo corregimiento se había subdividido en las provincias de Pallasca, Pomabamba y Huari, con sus respectivos distritos, los cuales se habían constituido sobre la base de las viejas doctrinas o parroquias coloniales, pero hubo también subdivisiones y alteraciones en la demarcación que condicionan los esfuerzos comparativos a través del tiempo. En el mapa siguiente se intenta presentar gráficamente esta evolución.

\footnotetext{
1 Además de la obra pionera de Fernando Silva Santisteban (1964), están los trabajos de alcance regional: Miriam Salas de Coloma (1998), Neus Escandell Tur (1997), Robson Brines Tyrer (1988).

2 Hemos utilizado en este trabajo documentos del Archivo Arzobispal de Lima (abreviado AAL) y del Archivo General de la Nación (AGN).
} 


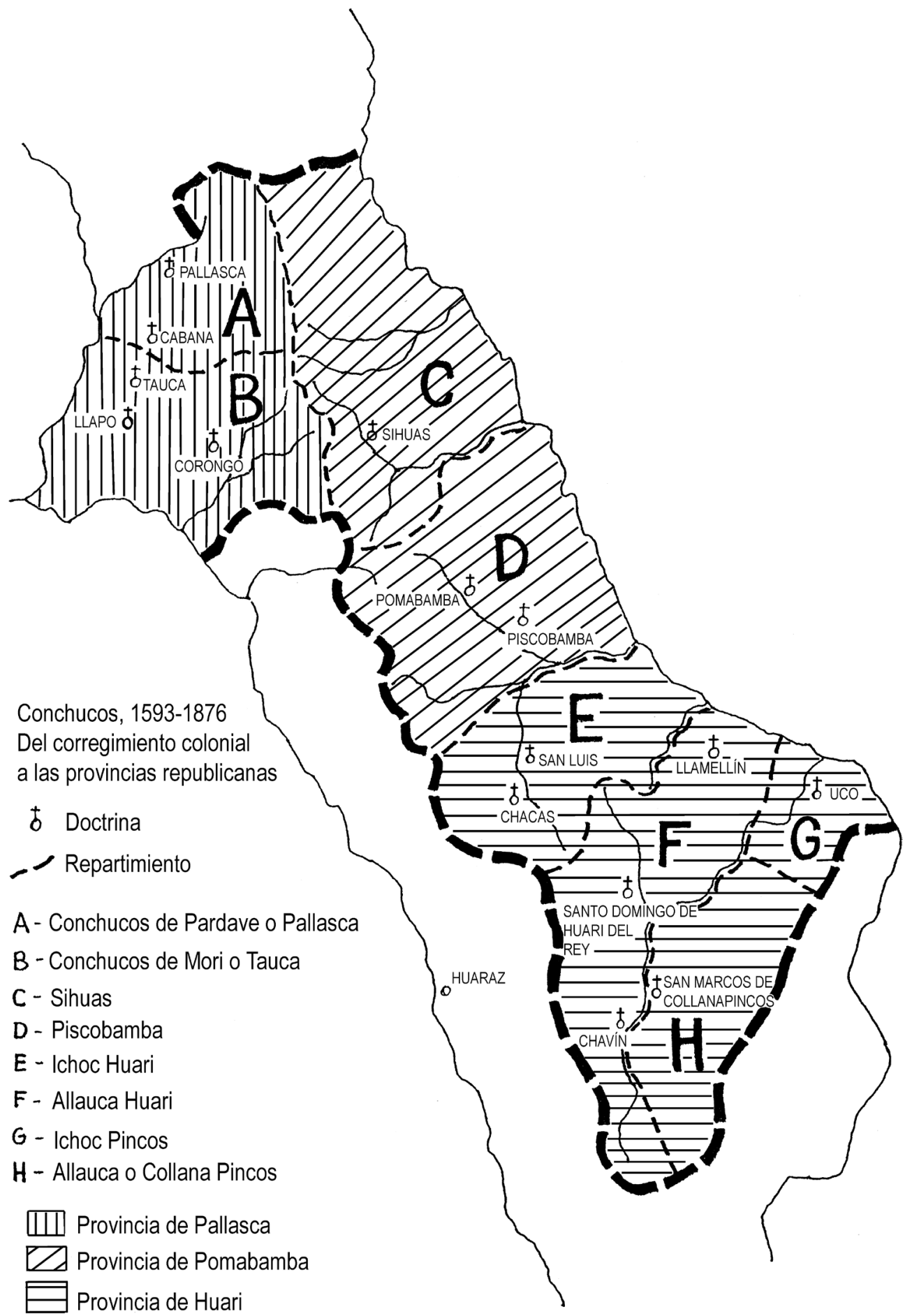


Fuera de los citados problemas de demarcación, está el contenido mismo de las fuentes que presentan categorías no equiparables. La visita de Mogrovejo se centra en la población indígena, y al presentar los datos de población de los obrajes no separa de manera clara la adscripción parroquial de los residentes y/o trabajadores en esos centros, ya que implícitamente la referencia es el repartimiento, es decir, la unidad que agrupaba en términos fiscales a los indios. Por esta razón, nuestro primer cuadro ha unido ciertas parroquias en una única referencia. En contraste, los datos de 1774 no se limitan a la población indígena de las parroquias, sino que incluyen también datos de la población mestiza, de la llamada española y de las castas. Los datos del censo de 1876 separan a la población por "raza": blanca, mestiza, india, negra y asiática. Pero los datos por tipo de asentamiento son globales; no hay manera de distinguir a los habitantes según la categoría "raza". Dicho censo reconoce dos tipos básicos de asentamiento: pueblos y caseríos. Dentro de esta última, se inscriben las haciendas. No se utiliza ya la denominación estancia ni existe ya el término "obraje" en la nomenclatura censal en esta área. De manera que no es posible trazar una comparación con los datos de 1593-1594 y 1774 que tenga directamente como base el perfil económico de un asentamiento. En cambio, para el efecto que nos interesa, hay datos sobre las "profesiones", que aunque no están desagregados por "raza", ni edad, al incluir los oficios de hilanderos, tejedores y tintoreros permiten construir un panorama del lugar que la manufactura textil ocupa en la economía regional. Curiosamente, se etiqueta como "sin profesión" a todas las personas de cualquier edad que no la declaren, con lo que incluso los niños párvulos contribuyen a inflar este porcentaje.

\section{PANORAMA DEL RAMO TEXTIL EN 1593-1594}

El gráfico 1 muestra, en términos porcentuales, la proporción de indígenas involucrados en los obrajes de Conchucos a fines del siglo XVI. Las primeras cinco columnas se refieren a las parroquias del norte del corregimiento, donde predominaban los obrajes de comunidad (vr Apéndice I, cuadro 1). Las cifras no se refieren solo a los trabajadores (hiladores, hiladoras, tejedores, etc.), sino al conjunto de personas (presumiblemente familias) con sus familias, en las que se cuentan no sólo las esposas y los hijos, sino los hombres y mujeres ancianos que cumplen tareas auxiliares para los trabajadores más jóvenes ${ }^{3}$. Esto apunta al hecho de que el obraje no era solo un centro de actividad económica, sino que en algunos casos se convirtió también en un centro de poblamiento con una importante irradiación en su entorno. El porcentaje global de población involucrada en los obrajes del corregimiento fue del 9,1 por cien en 1593-1594 (Apéndice II, cuadro 1).

\footnotetext{
3 Los llamados "muchachos" (jóvenes de doce a dieciocho años) se encargaban principalmente del hilado y eran parte importante del contingente laboral de un obraje. Por ejemplo, en el obraje A (ver Apéndice I, cuadro 1), situado en Pallasca, llegaban a conformar la mitad de los 140 trabajadores que laboraban allí hacia 1593 (Mogrovejo, 1920, pp. 265-266).
} 
El gráfico 1 presenta una imagen de este impacto según las parroquias. Los obrajes del norte del corregimiento eran más numerosos, pero probablemente de menores dimensiones y tuvieron un menor impacto en la estructura de distribución de la población (véase cuadro 1, obrajes de A a $\mathrm{H}$ ). Tauca y Llapo, donde la población adscrita a los obrajes llega al 10,3 por cien, son la excepción. Estas dos parroquias conjuntamente eran sede de tres obrajes. Curiosamente Corongo, que tenía dos obrajes, es una de las parroquias con menos población adscrita a estos establecimientos. Mucho más reducido es el impacto de los obrajes en Corongo que congregan solo a un 3,8 por 100 de la población indígena. Una posible explicación general para la reducida (comparativamente) cantidad de población india en obrajes del norte es el auge en estos años finales del siglo XVI del asiento minero de Atun-Conchucos (parroquia de Pallasca) así como de las minas de Colquepocro en el vecino corregimiento de Huaylas, que tenían asignada población mitaya procedente de Conchucos.

En cambio se puede decir que la zona centro y centro sur del corregimiento fueron las más vinculadas a los obrajes. El obraje K (posiblemente se trataba de San Bartolomé de Acopalca), cercano a la cabecera de la parroquia Santo Domingo de Huari del Rey (o Huari), congrega a indios tributarios del repartimiento de Allauca Huari y sus familias $^{4}$. Es un gran obraje y pertenece al común de indios. Los indios que vivían en este obraje llegaron a representar el porcentaje más alto frente al resto de parroquias: 15,1 por cien de la población india. De importancia algo menor son los obrajes de San Luis, Chacas y Llamellín, en donde se concentra el 12,7 de la población india de todas estas parroquias (repartimiento de Ichoc Huari), y el de Piscobamba, con 11,1 por cien, y que atrae población de esa parroquia y de las de Pomabamba y Sihuas (repartimiento de Piscobamba). En las parroquias del sur (San Marcos y Uco) correspondientes a los repartimientos de Allauca Pincos e Ichoc Pincos, los tributarios y familias parecen mucho menos condicionados por la labor obrajera.

4 Consúltese en el mapa la distribución de parroquias y repartimientos. 
1. Porcentaje de indios en obrajes, 1593-1594

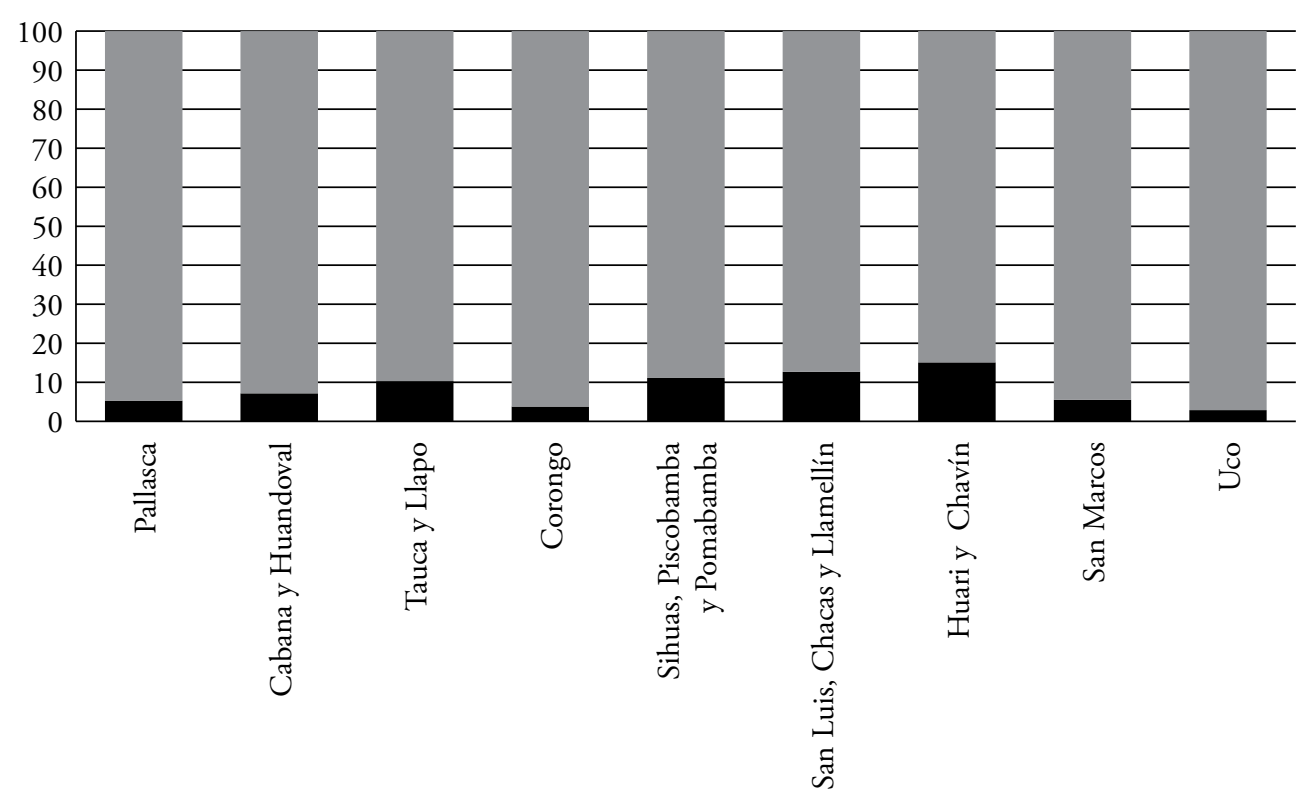

Indios en obrajes Indios en pueblos, haciendas y estancias

Fuente: Apéndice II, cuadro 1.

\section{PANORAMA DEL RAMO TEXTIL EN 1774}

Como se ha indicado, la novedad de los datos de 1774 con respecto a los de 1593-1594 es que corresponden al conjunto de la población: españoles, indios, mestizos y castas. El rasgo significativo es la reducida cantidad de personas que aparece vinculada a la economía del obraje: 3,2 por cien del total. Además los obrajes como centros poblados parecen haber perdido importancia en todas las parroquias del norte. Sin embargo, si tomamos solo como referente solo a la población indígena, el panorama cobra un sesgo diferente. Es claro que frente al 9,1 de indios vinculados a obrajes en 1593-1594, el porcentaje de 5,6 en 1774 indica claramente un retroceso. No obstante, la vinculación con el obraje dejó una marca clara en la demografía indígena ${ }^{5}$, en cambio solo el 0,2 por 100 de españoles y el 0,78 por 100 de mestizos se asentaron en obrajes (Apéndice II, cuadro 3).

En lo concerniente a la zonificación de este ramo, parece también que la empresa obrajera tiene irradiación relevante en la zona central y meridional del corregimiento. En Pomabamba la población adscrita a obrajes llega a más del 10 por cien y en Piscobamba al 8 por cien. En el sur, sobre todo Santo Domingo de Huari, el pueblo

5 Puede consultarse sobre las tendencias demográficas en el área: Magdalena Chocano (2006, pp. 129-160). 
más importante del corregimiento, conserva su vieja vinculación obrajera con un 10 por cien de población adscrita a este sistema. Lo acompańa en este punto la parroquia de San Luis (Apéndice II, cuadro 2). Por tanto, puede decirse que en el último tercio del siglo XVIII la producción textil en obrajes se había concentrado en esta zona central y sur del corregimiento, acentuando una tendencia posiblemente perceptible en los datos de 1593-1594, en los que es apreciable la mayor incidencia demográfica del obraje en estas zonas que en las del norte.

\section{Porcentaje de población residente en obrajes, pueblos y haciendas del corregimiento de Conchucos, 1774}

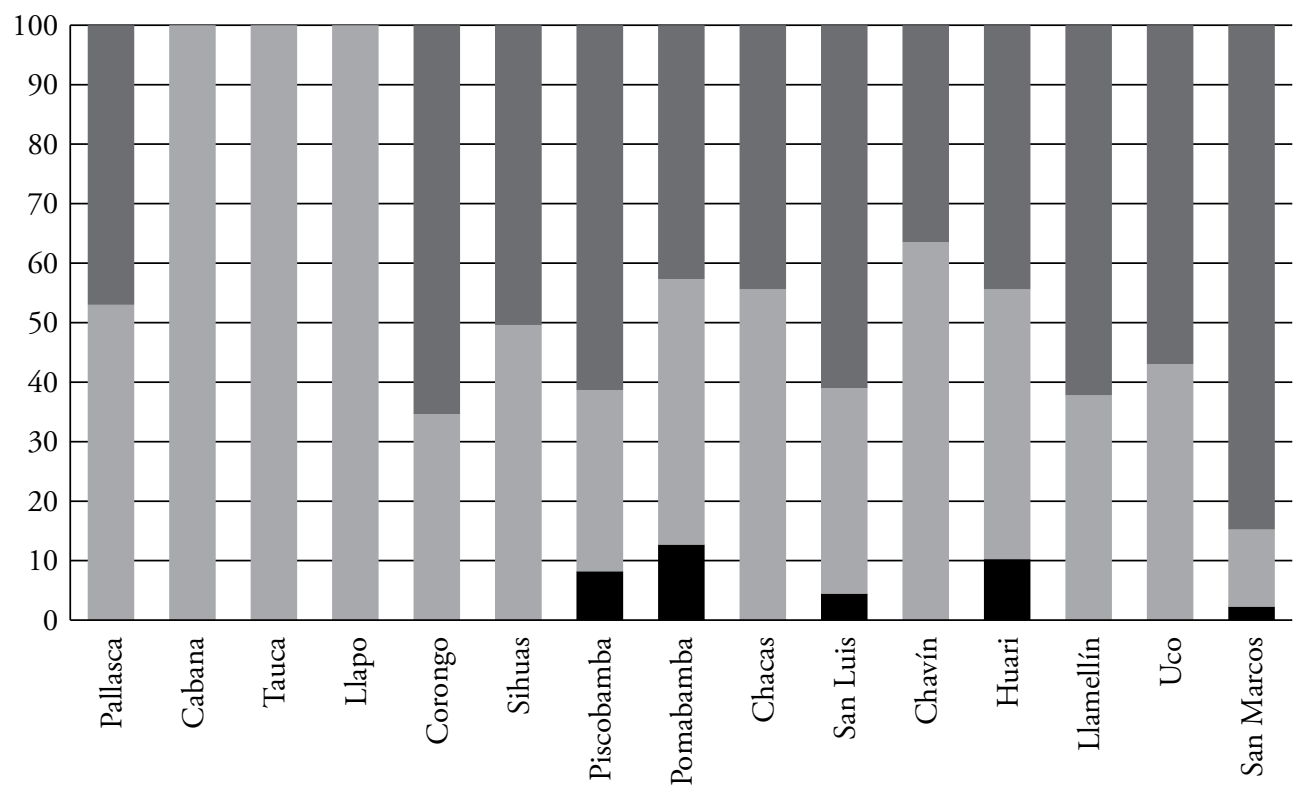

- Población en obrajes Población en pueblos a Población en haciendas y estancias

Fuente: Apéndice II, cuadro 4.

Otras fuentes pueden contribuir a ofrecer una hipótesis explicativa: A raíz de la epidemia de 1720 , se ordenó una visita en el corregimiento para revisar el número de tributarios. El visitador Diez de Medina, afirma que la disminución poblacional que registró en 1725, con respecto a la revisita del año 1677 (documento que no hemos hallado), no fue compensada en los repartimientos de Pallasca ni de Tauca, debido a que no tenían haciendas de españoles que eran los asentamientos que solían "agregar" (incorporar) efectivos y que, por tanto, podían equilibrar la disminución sufrida por el número de los originarios (Diez Medina, carta de 12 de mayo de 1726, en: AGN, Tributos, leg. 2, cuad. 16). Si tomamos en cuenta que varios obrajes del norte del corregimiento estaban en manos de comunidades, y que según los informes fue notable la disminución 
de originarios, precisamente el segmento que con su trabajo garantizaba su rentabilidad, puede suponerse que este factor hizo perder importancia a dichos obrajes. Los obrajes del sur no estuvieron exentos de dicho problema. Este mismo visitador afirma que el obraje de Acopalca, situado en las inmediaciones de Huari y que pertenecía al común, como se ha señalado antes, no se podía arrendar al precio habitual de 900 pesos (de a ocho reales) porque la población había caído a la mitad. Si tomamos en consideración que los obrajes a cuyos aprietos se refiere el visitador son obrajes de comunidad (más numerosos en el norte que en el sur), puede pensarse que para la mayoría de ellos la epidemia y las pérdidas de población que trajo significaran un punto de no retorno. De todos modos, Acopalca, en el sur siguió siendo importante tal como lo corrobora el hecho que contara con 235 habitantes, más del 10 por cien de la población de la parroquia (ver Apéndice II, cuadro 3).

La importancia de los obrajes en cuanto empresas parece haber decaído en el corregimiento. Aunque no se puede ser concluyente, no parece posible que esta disminución de obrajes fuera equilibrada por la producción realizada en obrajillos y chorrillos, y en los hogares campesinos. Un indicio puntual sobre el embargo del obraje de san Francisco de Yurma, situado en Piscobamba, el corregidor Joseph Taboada y Castilla, encargado de dicha diligencia explica: "esta provincia es pobre y de muy pocos sujetos facultados. Los obrajes están en una total decadencia por el poco valor de la ropa de la tierra, por lo que ay en esta misma provincia muchas fincas de esta naturaleza abandonadas y sin tener los dueños a quien arrendarlas de que tengo muchos ejemplares que pudiera hazer presentes a U.S. lo que executo por no molestarle..." (AGN, Juzgado de la Caja General de Censos, leg. 34, carta Piscobamba, 6 de noviembre de 1777). Es probable que la demanda de tejidos de la propia provincia fuera satisfecha por algunos obrajes todavía operativos y por la producción de nivel doméstico. El auge minero de Cerro de Pasco de fines del siglo XVIII e inicios del siglo XIX probablemente dinamizó la producción textil local, aunque la documentación pertinente no es lo bastante continua para definir los alcances de esta posibilidad.

\section{EL RAMO TEXTIL EN 1876: UN RETRATO A TRAVÉS DE LAS “PROFESIONES”}

El censo de 1876 no menciona ningún obraje, ni establecimiento de manufactura textil. Como se ha señalado, reconoce como asentamientos solo pueblos y caseríos, y dentro de estos indica su calidad de haciendas entre paréntesis. En cambio hay datos en la estadística titulada "Profesiones", donde figuran personas que declaran los siguientes oficios vinculados con el ramo del tejido: hilanderas e hilanderos, tejedores y tejedoras, $y$, tintoreros y tintoreras. 


\section{Porcentaje de "profesiones" vinculadas con el ramo textil en la demarcación del antiguo Conchucos, en distritos de 1876}

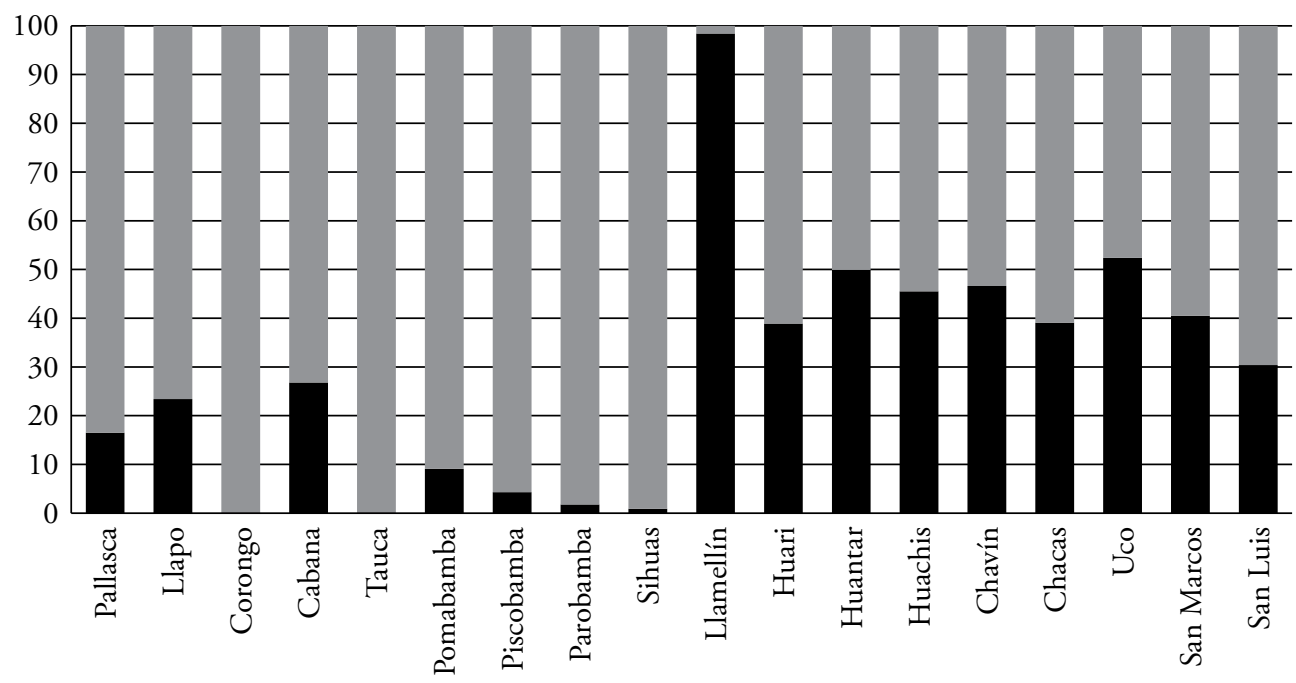

— "Profesiones" vinculadas al ramo textil "Profesiones" no vinculadas al ramo textil

Fuente: Apéndice II, cuadro 5.

No es posible correlacionar estos datos censales con establecimientos específicos donde se realizara la confección de tejidos, ya que no aparece ninguno indicado como tal. Lo curioso es que a través de otras fuentes se tienen indicios de la existencia de establecimientos de cierta envergadura dedicados a la manufactura textil. Por ejemplo, aunque en la provincia de Corongo no existe ninguna persona que haya declarado como profesión algún ramo ligado a la textilería, se decía en un informe prefectural de 1874 que Urcón, sede de un obraje colonial, producía "paños de buena calidad". Su propietario, don Jacinto Terry, era además subprefecto de la provincia de Pallasca (Carrillo y Ariza, 1994, p. 9). El viajero francés Wiener relató que en Urcón llegó a desarrollarse la producción fabril de tejidos, pero en el censo de 1876 la localidad aparece simplemente como hacienda con un total de 339 habitantes, 169 hombres y 170 mujeres, sin la más mínima referencia a su carácter industrial ${ }^{6}$. Los cien operarios y las máquinas máquinas europeas de acero movidas con fuerza hidráulica que Wiener vio, sencillamente no figuran como tales en el distrito de Corongo (Wiener, 1880, p. 178). Es probable que los funcionarios que levantaron el censo de 1876 y el propio gestor o dueño de la manufactura no viera en los trabajadores de ese centro operarios u obreros sino peones de hacienda. Interesante resulta que la fábrica producía prendas para la tropa. Observamos en la época republicana el aprovechamiento de una posición política en el aparato del estado para obtener una ganancia económica, tal como había sido la práctica de los funcionarios

6 Censo General de la república del Perú formado en 1876 (1878, p. 403). 
coloniales, en especial, los corregidores. Antes de la guerra con Chile, la familia Terry había contratado a un técnico alemán apellidado Bergmann, procedente de la localidad de Elberfeld. La producción, según informa el viajero alemán Middendorf consistía en burdas telas, elaboradas con la lana procedente del ganado de la hacienda. La guerra arruinó la existencia del ganado y la producción textil cesó, y el propio técnico emigró al Marañón como buscador de oro. Probablemente con la desorganización de la posguerra la confección para la tropa sufrió también un descenso. De todos modos, aunque no sabemos si siguió ligada a la demanda del estado, la producción parece haberse recuperado en algún momento de la posguerra, pues los herederos de Terry pleiteaban por sus derechos a una parte de la fábrica de tejidos en el llamado "obraje de Urcón" (AGN, Protocolos notariales, Escribano Carlos Rosas Morales, Protocolo 658, 1897, f. 240).

Fuera del caso anómalo de Corongo y la excepción de Tauca, donde parecen haberse desterrado los oficios del ramo textil, los demás distritos presentan diversos niveles de implicación de su población en las profesiones vinculadas con el tejido. En los distritos del norte, el porcentaje de tejedores, hilanderos y tintoreros es reducido comparado con las proporciones que presentan estos oficios en el sur del antiguo corregimiento. Datos de 1848 indican que en Cabana había una producción bayetas, jergas, mantas y pequeńas piezas de muy baja calidad y reducida cantidad, por lo que apenas bastaban para abastecer a los lugareños (AAL, Visitas leg. 6, exp. 27, 9 de diciembre de 1848).

Llama la atención que también los distritos correspondientes al centro del antiguo Conchucos, otrora bastante vinculados a la producción obrajera, presenten un limitado contingente ocupado en oficios textiles. La información de 1848 sobre la manufactura textil en Pomabamba es poco alentadora: "Los ponchos, polaynas, fajas, guantes y otros renglones en que se ocupaban ya no se trabajan, porque introducen los extranjeros de mejor fábrica en precios bajos pero de poca duración" (AAL, Visitas, leg. 6, 30 de noviembre de 1848, por José Eulalio López). Pese a ello, se sabe que el obraje colonial de Andaymayo se mantenía activo, aunque no parece haber llegado a modernizar su equipamiento. Quizá incluso tuviera algún impacto distrital, ya que hay un 9.1 por cien de personas dedicadas a profesiones ligadas al tejido en Pomabamba representa la proporción más alta en la zona central del antiguo corregimiento. La guerra con Chile no lo afectó tanto, ya que Middendorf da noticias de su actividad en manos de la familia Cisneros. Sus telares beneficiaban la lana producida en la misma hacienda y producían (quizá entre otros géneros) alfombras de cuadros rojos, amarillos y blancos de uso doméstico y local (1973, pp. 27-30). Andaymayo no parece haber dependido de la vinculación con el estado para conseguir una demanda de sus productos, sino más bien del mercado local y regional.

En cambio en el sur del mismo, equivalente a la provincia republicana de Huari, el porcentaje de personas ocupadas en labores ligadas al tejido es muy alto, al punto que en el distrito de Llamellín parecen ser la ocupación de casi todos los que se dedican a alguna profesión. Raimondi, que describió el departamento de Ancash hacia 1856, 
no destacó ninguna localidad de estas provincias por su manufactura textil, a excepción de Sihuas, por la confección de ponchos. Es posible que Raimondi dejara de registrar la actividad textil en otros distritos, ya que parece haberle interesado sobre todo la producción minera. De todos modos, en el censo de 1876, veinte años después, no parece haber habido en Sihuas nadie que considerara su labor textil lo suficientemente importante para declararla como "profesión".

Aunque de San Marcos no se caracterizó en el siglo XVIII por estar entre las parroquias que más población mantenían ligada al sistema de obrajes, en el siglo XIX la destinó su producción de lana a fabricar bayetas que eran "rescatadas" (este término puede hacer referencia al trueque) por comerciantes procedentes de Huaraz y Recuay, así como ponchos y frazadas que se llevaban a vender a las montañas y otros puntos (no especificados). El cura de esta parroquia no informa sobre los productores, pero señalaba que los precios eran bajísimos y decadentes en relación a tiempos anteriores (AAL, Visitas, leg. 6, exp. 20, 31 de diciembre de 1848).

Otro aspecto notable es el alto porcentaje de mujeres dedicadas a este ramo de la producción. En la época colonial era el empleo de jóvenes, específicamente muchachos en la tarea del hilado (ver nota 2). Parece que este tipo de ocupación desapareció entre los hombres en el siglo XIX, ya que casi no se registran hilanderos. Esto se pudo deber a la incidencia de un nuevo orden republicano en que se impuso el enrolamiento en el ejército para el sector joven masculino, lo cual también probablemente feminizó la labor de hilandería.

4. Número de hombres y mujeres en profesiones del ramo textil, 1876

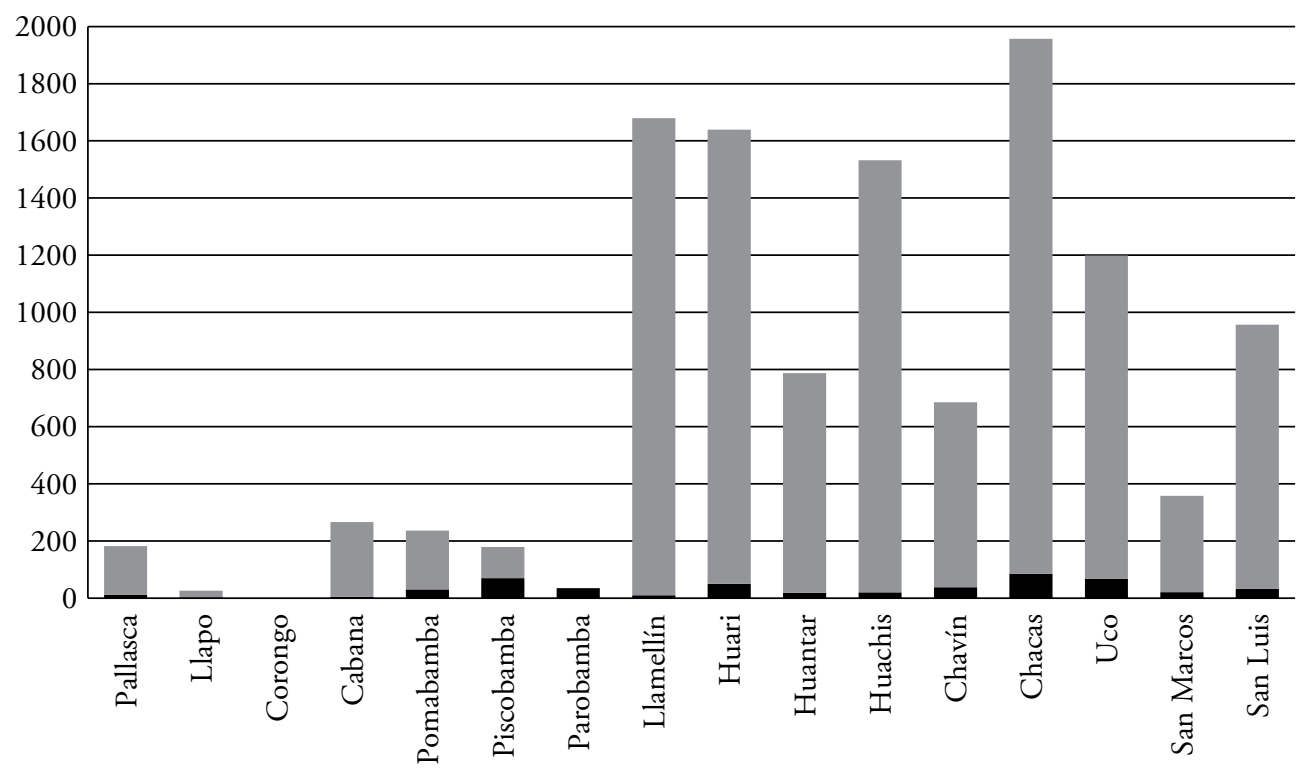

Hombres con profesiones del ramo textil $\square$ Mujeres con profesiones del ramo textil 
Datos de tipo cualitativo sugieren un proceso de feminización de la textilería local en ciertas áreas. En 1848, el cura de Cabana informaba que la labor del tejido corría ya exclusivamente a cargo de las mujeres, las cuales sufrían constantes malos tratos físicos. El cura que suscribe este informe, José Antonio Capelo, reiteradamente critica a los hombres de Cabana por "gobernar" a las mujeres no "por principios de razón sino a fuerza de golpes". La asociación entre trabajo textil y violencia física parece haberse mantenido incluso en condiciones de retroceso de la manufactura local, trasladada al núcleo doméstico: "Las personas que en Cabana se estiman por más visibles visten de estas telas capas, chaquetones y calzones, preparados por sus mismas consortes, obligadas acaso al rigor de mortales golpes”. (AAL, Visitas leg. 6, exp. 27, 9 de diciembre de 1848).

\section{APUNTES FINALES}

Los obrajes coloniales de Conchucos parecen haber experimentado una tendencia similar a la señalada para otras regiones andinas. Es decir, la decadencia de los obrajes de comunidad y una concentración de la producción textil en los obrajes en manos privadas a mediados del siglo XVII (Miño Grijalva, 1993, pp. 125, 137-138). No obstante, en Conchucos es probable que el deterioro final de los obrajes de comunidad ocurriera a raíz de la gran epidemia de 1720 . Por otra parte, los obrajes en manos privadas tampoco parecen haber experimentado un auge uniforme en Conchucos. Hay indicios de que algunos debieron abandonar totalmente el ramo textil y recuperar su rol de simples haciendas, incluso en el último cuarto del siglo XVIII en que ocurre un auge minero en la sierra central.

Durante la república el sistema textil basado en los obrajes no superó ni la dislocación motivada por las guerras civiles ni la competencia de géneros extranjeros. Unos pocos, dos en el caso de Conchucos, se reconvirtieron en una suerte de fábricas textiles, pero su impacto resultó limitado. En cambio, la manufactura doméstica y local, pese a la competencia y baratura de los géneros textiles importados, parece haber resistido en buena medida e incluso haber dado ocupación a muchas personas. Es probable que el disímil nivel de ocupación en el ramo textil entre las zonas norte y centro y la sur en el territorio que fue el corregimiento de Conchucos se deba al distinto nivel de penetración de los circuitos mercantiles. De manera que el norte, principalmente, puede haber sido más susceptible a la introducción de tejidos extranjeros, mientras que el centro y el sur, mantuvieron el mercado local abastecido por los productores locales e incluso lograron exportar a sus vecinos inmediatos. 


\section{APÉNDICES}

\section{Apéndice I}

¿Cuántos obrajes? ¿dónde? ¿cuándo?: pistas, incongruencias y vacíos

Según la visita de 1593, en el corregimiento había quince establecimientos denominados obrajes, algunos de los cuales pueden ser identificados hipotéticamente. Llama la atención que en el extremo noroeste se hayan concentrado ocho obrajes, más de la mitad de los existentes en el corregimiento en esa fecha. Los restantes seis obrajes se distribuyen entre el centro y el sur del corregimiento.

Cuadro 1. Obrajes en las parroquias del corregimiento de Conchucos, 1593-1594

\begin{tabular}{|c|c|c|c|c|}
\hline Clave & Propiedad & Propietario & Situación & Nombre/Observaciones \\
\hline A & Comunidad & Común de Pallasca & $\begin{array}{l}\text { "a dos tiros de arcabuz" de } \\
\text { pueblo de Pallasca }\end{array}$ & \\
\hline$\underline{\mathrm{B}}$ & Comunidad & Común de Huandoval & Huandoval & \\
\hline$\underline{\mathrm{C}}$ & Comunidad & Común de Cabana & Cabana & \\
\hline $\mathrm{D}$ & Comunidad & $\begin{array}{l}\text { Comunes de Tauca y } \\
\text { Llapo }\end{array}$ & $\begin{array}{l}\text { entre pueblos de Tauca y } \\
\text { Llapo }\end{array}$ & $\begin{array}{l}\text { Administrado por } \\
\text { Hernando de Mori }\end{array}$ \\
\hline$\underline{\mathrm{E}}$ & Privada & Hernando de Chávez & junto a Tauca & $\begin{array}{l}\text { "Santa Catalina de } \\
\text { Caxamarca"* }\end{array}$ \\
\hline $\mathrm{F}$ & Privada & Hernando de Chávez & en la plaza de Llapo & \\
\hline G & Privada & Hernando de Chávez & Corongo & \\
\hline$\underline{\mathrm{H}}$ & Privada & Diego de Pardave & Corongo & San Antonio de Urcón? \\
\hline$\underline{\mathrm{I}}$ & Privada & Josefa Serna & a 1 legua de Piscobamba & $\begin{array}{l}\text { San Sebastián de } \\
\text { Acobamba? }\end{array}$ \\
\hline I & Privada & Lic. Diego Álvarez & a 2 leguas de Chacas & Santiago de Aurinja \\
\hline$\underline{\mathrm{K}}$ & Comunidad & $\begin{array}{l}\text { Común de Sto. Domingo } \\
\text { de Huari del Rey }\end{array}$ & $\begin{array}{l}\text { a } 1 / 2 \text { legua de Sto. } \\
\text { Domingo de Huari del Rey }\end{array}$ & $\begin{array}{l}\text { San Bartolomé de } \\
\text { Acopalca? }\end{array}$ \\
\hline $\mathrm{L}$ & Privada & Don Joan Guaman-guanca & 1 legua de Yaquia & \\
\hline$\underline{\mathrm{M}}$ & Privada & Pedro Espinosa & $\begin{array}{l}\text { a } 3 \text { leguas de San Marcos } \\
\text { de Collanapincos }\end{array}$ & $\begin{array}{l}\text { San Juan Bautista de } \\
\text { Patay }\end{array}$ \\
\hline $\mathrm{N}$ & Privada & $\begin{array}{l}\text { Encomendero Gaspar de } \\
\text { Espinosa }\end{array}$ & Uco & \\
\hline $\mathrm{O}$ & Privada & $\begin{array}{l}\text { Cacique principal de Ichoc } \\
\text { Pincos }\end{array}$ & $\begin{array}{l}\text { en Nuestra Señora de } \\
\text { Guadalupe, a } 1 \text { legua de } \\
\text { Huachis }\end{array}$ & \\
\hline
\end{tabular}

* Nombre con que aparece en BNL, B 1113.

Fuente: Elaborado por la autora con datos de Toribio de Mogrovejo, arzobispo, "Libro de visitas. Visita de 1593". Revista del Archivo Nacional, tomo 1 y 2 (Lima, 1920), pp. 264-279 y 401-419, Francisco López de Caravantes, Noticia general del Perú (Madrid: Atlas, 1965), vol. 1, p. 127 (subrayados). 
Esta imagen puede ser alterada o complementada con investigaciones en fuentes como los protocolos notariales ${ }^{7}$. La inexistencia de fuentes posteriores equiparables a la visita de Mogrovejo impide seguir la evolución de la distribución de obrajes en la provincia. Las Noticias del Perú de López de Caravantes proceden de inicios del siglo XVII, e informan de la existencia de solo nueve obrajes (subrayados en el cuadro 1) en Conchucos, por lo que parecería que en un lapso bastante corto hubiera ocurrido una notable disminución de obrajes en el corregimiento. Los datos procedentes de otros documentos sugieren un panorama menos drástico, pese a notorias incongruencias en la nomenclatura: algunas veces un obraje es denominado hacienda, mientras que en un momento anterior o posterior aparece como hacienda y obraje, u obraje. Tampoco las fuentes más o menos contemporáneas coinciden en incluir las mismas propiedades bajo una etiqueta uniforme.

Para disponer de información de nivel provincial sobre los obrajes hay que esperar hasta el último tercio del siglo XVIII, aunque no hay siempre coincidencia entre las fuentes sobre los topónimos. Las matrículas de tributarios registran solo siete establecimientos textiles:

\section{Cuadro 2. Obrajes y chorrillos indicados en las matrículas de tributos del corregimiento de Conchucos, 1788-1815}

\begin{tabular}{lll}
\hline \multicolumn{1}{c}{ Denominación } & Repartimiento & \multicolumn{1}{c}{ Parroquia de referencia } \\
\hline Obraje de San Antonio de Urcón* & Pallasca/ Tauca & San Juan Bautista de Pallasca/Tauca \\
Hacienda y obraje de Santa Clara & Sihuas & Santa María de las Nieves de Sihuas \\
Chorrillo de Chaupirca [Chaupuirga] & Piscobamba & Piscobamba \\
Obraje de San Bartolomé de Acopalca & Allauca Huari & Santo Domingo de Huari \\
Obraje de San Juan Bautista de Maraibamba & Ichoc Huari & San Luis de Huari \\
Obraje de Santa Inés de Uchusquillo & Ichoc Huari & San Luis de Huari \\
Chorrillo de Cacaray & Ichoc Huari & San Miguel de Chacas \\
\hline
\end{tabular}

*Este establecimiento aparece como obraje de Pallasca en las matrículas de 1788 y 1793. En 1788 se registra también una hacienda de Urcón para Tauca, pero no aparece ya en 1793. De 1798 a 1815 el obraje de Urcón aparece atribuido al repartimiento de Tauca y no más en la lista de Pallasca.

Fuente: Elaborado por la autora con datos de AGN, Tributos, leg. 4, cuad. 75, 93, 110, 122 y 140.

\footnotetext{
7 Hacia 1600 existen noticias de un obraje de Yuncay o Juncay en Piscobamba (llamado Yungay en las fuentes del XVI) que estaba en poder Joseph de la Serna, descendiente del encomendero Miguel de la Serna (Miguel León, Paños e hidalguía: Encomenderos y sociedad colonial en Huánuco, 1540-1640. Lima: Instituto de Estudios Peruanos, 2002, p. 110). Pensamos que no se trata del obraje I de la lista basada en la visita de 1593, porque la distancia de Yuncay o Yungay con respecto a Piscobamba es aproximadamente tres leguas, mientras que el obraje de Acobamba (I en la lista) sí estaba situado aproximadamente a una legua de Piscobamba. En las listas de tributos de 1790 en adelante se identifica un topónimo "Juncay" en las listas del repartimiento de Ichoc Huari (por ejemplo, AGN, Tributos, leg. 4, cuad. 75), pero no como obraje sino como hacienda. Este caso ilustra las dificultades de conciliar descripciones de la época, que muchas veces dan referencias muy vagas, y topónimos que aparecen y desaparecen en las fuentes. Otras noticia procedente de Piscobamba se refiere al obraje de Vilcabamba que no figura en la visita de Mogrovejo, aunque parece haber sido propiedad también de un descendiente del encomendero La Serna (AAL, Capítulos, leg. 24, exp. 2).
} 
Se aprecia un fuerte cambio en la distribución espacial de los obrajes, al menos de aquellos legalmente constituidos y que respondían como tales a efectos fiscales: a fines del siglo XVIII e inicios del XIX, la mayoría de obrajes se ubica en el centro sur de la provincia, mientras que en el norte solo se mantiene activo el antiguo obraje de Urcón, y ha surgido el gran obraje de Santa María de Sihuas en un repartimiento que, a fines del siglo XVI, no registraba ningún establecimiento textil en la documentación oficial ${ }^{8}$. Una razón por la que los obrajes de comunidad predominantes en el norte del corregimiento no aparecen en los registros de tributarios puede deberse a que, al estar ubicados en los mismos pueblos o reducciones, no se convirtieron en un asentamiento diferenciado y por eso mismo no se les dio una denominación específica. Existían, pues, en una probable simbiosis espacial con los pueblos indios, lo que no ocurría con los obrajes-hacienda.

Los padrones parroquiales corroboran a grandes rasgos esta distribución espacial de los obrajes, aunque indican obrajes que no aparecen en las matrículas de tributos: salvo Acopalca, no parece que se refieran a la misma provincia. También cambia a veces la asignación de la función del lugar: lo que en la documentación fiscal se señala como hacienda o estancia en el padrón parroquial aparece indicado como obraje y hacienda, u obraje simplemente: Urcón, listado como obraje en las matrículas de tributos, aparece como hacienda en el padrón de la parroquia de Corongo. Tanto las matrículas de tributos como los padrones de parroquias coinciden en no mencionar obrajes, comunales o privados, de las parroquias del norte, a excepción del ya mencionado Urcón.

Cuadro 3. Obrajes indicados en los padrones de las parroquias del corregimiento de Conchucos 1774-1815

\begin{tabular}{llc}
\hline \multicolumn{1}{c}{ Denominación } & \multicolumn{1}{c}{ Parroquia } & \multicolumn{1}{c}{$\begin{array}{c}\text { Años } \\
\text { documentados }\end{array}$} \\
\hline Obraje de San Antonio de Urcón & Corongo & $1788^{*}$ \\
Obraje de Nra. Sra. de la Candelaria de Vilcabamba & Piscobamba & 1774 \\
Hacienda y obraje San Francisco de Yurma & Piscobamba & 1777 \\
Hacienda y obraje de Santa Catalina de Andaymayo & Pomabamba & $1774-1777$ \\
Hacienda y obraje de San Antonio de Chinchobamba & Pomabamba & $1774-1777$ \\
Obraje de San Bartolomé de Acopalca & Santo Domingo de Huari & $1774-1777$ \\
Obraje de Santiago de Aurinja & San Luis de Huari & $1769-1813$ \\
Real obraje de Nra. Sra. de Copacabana de Cochao & Chavín & $1774-1815$ \\
Obraje de San Juan Bautista de Patay & San Marcos de Collanapincos & 1774 \\
\hline
\end{tabular}

* En 1774 y 1777 aparece como hacienda.

Fuente: Elaborado por la autora con datos de AAL, Visitas, leg. 4, exp. 13, 15, 23 y 25; leg. 5, exp. 1, 3, 5, 10, 12, 13, 15, 17, 18 y 24; Estadística, leg. 2, exp. 18, 19, 22 y 32; leg. 4, exp. 16 y 42.

8 En una información sobre el desempeño del cura de Sihuas, licenciado Francisco de Cisneros y Mendoza, aparece como testigo el sargento mayor de la provincia de Conchucos, Antonio Verde de Leguisamo, natural de Toledo, como dueño del obraje de Santa Clara de Buenavista (AGI, Lima 264, n 26). Podría tratarse del obraje indicado en el cuadro 2. 
Si tomamos los datos de fincas encabezonadas (es decir, que pagaban la alcabala de cabezón, una especie de impuesto predial), advertimos que tampoco se registra en las parroquias norteñas de Pallasca, Tauca, Cabana y Llapo, ninguno de los obrajes que en 1593 aparecieron estrechamente vinculados a los pueblos indios. Comparten antigüedad con Urcón, los obrajes del sur de Aurinja, Acopalca y Patay. Los demás parecen haber sido fundados con posterioridad. El monto del cabezón puede ser un indicio de la importancia económica del establecimiento. Los obrajes que pagan cien pesos y más por año son: Urcón en Corongo, Santa Clara y Jocos en Sihuas, Yurma y Vilcabamba en Piscobamba, Andaymayo y Pasacancha en Pomabamba ${ }^{9}$, Uchusquilla en San Luis.

Cuadro 4. Obrajes sujetos a alcabala de cabezón, 1779-1784

\begin{tabular}{|c|c|c|c|c|c|c|}
\hline Propiedades afectadas & & 1779 & 1779 & 1780 & $\begin{array}{l}1783- \\
1784\end{array}$ & $\begin{array}{l}1783- \\
1784\end{array}$ \\
\hline & $\underline{\text { Parroquia }}$ & $\underline{\text { Monto fijado }}$ & $\underline{\text { Deudas }}$ & $\underline{\text { Deudas }}$ & $\underline{\text { Pagos }}$ & $\underline{\text { Deudas }}$ \\
\hline Obraje de San Antonio de Urcón & Corongo & 200 & & 600 & & \\
\hline [Hacienda de Santa Clara] & Sihuas & s.d. & & 200 & & \\
\hline Obraje de Jocos & Sihuas & s.d. & & 200 & 100 & \\
\hline Obraje de San Juan de Yurma & Piscobamba & s.d. & & & & 600 \\
\hline $\begin{array}{l}\text { Obraje de Nra. Sra. de la Candelaria } \\
\text { de Vilcabamba }\end{array}$ & Piscobamba & s.d. & & & & 200 \\
\hline $\begin{array}{l}\text { Obraje de Santa Catalina de } \\
\text { Andaymayo y Santiago de Pasacancha }\end{array}$ & Pomabamba & 145 & & & 435 & \\
\hline $\begin{array}{l}\text { Obraje de San Juan Bautista de } \\
\text { Maraibamba }\end{array}$ & San Luis & 12 & & & 24 & \\
\hline [Estancia de Chaupirga] & Chacas & 4 & & & -- & pendiente \\
\hline Obraje de Santa Inés de Uchusquilla & San Luis & 100 & & & 300 & 100 \\
\hline Obraje de Santiago de Aurinja & San Luis & 10 & & & 20 & \\
\hline Obraje de San Bartolomé de Acopalca & Huari & 40 & 40 & 5 & 80 & \\
\hline $\begin{array}{l}\text { Obraje de Nra. Sra. de Copacabana } \\
\text { de Cochao }\end{array}$ & Chavín & 20 & & & 40 & \\
\hline Obraje de San Juan Bautista de Patay & San Marcos & 10 & 5 & 5 & 20 & \\
\hline
\end{tabular}

Fuente: Elaborado por la autora con datos de AGN, Aduanas, C-16, cuaderno 1245.1 (1779-1780) y 1247.35 (1783-1784)

Entre estos establecimientos, Urcón, cerca de Corongo, fue el obraje que pagaba el cabezón más elevado. Los obrajes de menos entidad predominan claramente en las parroquias del sur: Aurinja y Maribamba en San Luis deben pagar entre diez y doce pesos a la real caja. En Huari, el antiguo obraje de Acopalca, propiedad de los indios del repartimiento de Allauca Huari, llega a pagar cuarenta pesos, lo que lo convierte en el más importante de los pequeños. Patay, cuya fundación data al menos de 1593

\footnotetext{
9 Andaymayo aparece como "asiento" en un expediente de remate de una mina situada en Sihuas en 1679. Efectivamente, la propiedad estuvo asociada a la mina también denominada Pasacancha (AGN, Minería, leg. 61, exp. sin número).
} 
( $M$ en cuadro 1), paga diez pesos y también es un contribuyente menor, lo mismo vale para Aurinja, obraje del siglo XVI, que paga igual cantidad. Con veinte pesos de cabezón, el obraje de Cochao, posiblemente fundado en el siglo XVIII, entrega un aporte intermedio entre estos obrajes menores. En esta lista de fincas gravadas no aparece el chorrillo de Chaupuirga, que, en cambio, aparece en las matrículas de tributarios sin falta entre 1788 y 1809 (ver Apéndice I, cuadro 2). El chorrillo de Cacaray, listado en las matrículas de Ichoc Huari, aparece en las listas de alcabala de cabezón como estancia de la parroquia de Chacas y paga solo cuatro pesos, y acumula deudas no especificadas para 1783-1784.

\section{Apéndice II}

Cuadro 1. Indios censados en los obrajes de las doctrinas del corregimiento de Conchucos en 1593-1594

\begin{tabular}{lcccc}
\hline \multicolumn{1}{c}{ Parroquias } & $\begin{array}{c}\text { Población } \\
\text { india }\end{array}$ & $\begin{array}{c}\text { Indios } \\
\text { en obrajes }\end{array}$ & $\begin{array}{c}\text { Porcentaje } \\
\text { de indios en obrajes }\end{array}$ & $\begin{array}{c}\text { Número } \\
\text { de obrajes }\end{array}$ \\
\hline Pallasca & 2670 & 140 & 5,3 & 1 \\
Cabana y Huandoval & 1567 & 114 & 7,2 & 2 \\
Tauca y Llapo & 3137 & 324 & 10,3 & 3 \\
Corongo & 1592 & 62 & 3,8 & 2 \\
Subtotal (norte) & 8966 & $\mathbf{6 4 0}$ & 7,1 & 8 \\
Sihuas, Piscobamba y Pomabamba & 3715 & 415 & 11,1 & 1 \\
Subtotal (centro) & 3715 & 415 & 11,1 & 1 \\
San Luis, Chacas y Llamellín & 2769 & 332 & 12,7 & 1 \\
Huari y Chavín & 2534 & 384 & 15,1 & 1 \\
San Marcos & 1376 & 77 & 5,5 & 1 \\
Uco & 1680 & 50 & 2,9 & 2 \\
Subtotal (sur) & 8359 & 843 & 10,1 & 5 \\
\hline Total & 21040 & 1921 & 9,1 & 14 \\
\hline
\end{tabular}

Fuente: Elaborado por la autora con datos de Toribio de Mogrovejo, arzobispo, "Libro de visitas. Visita de 1593". Revista del Archivo Nacional, tomo 1 y 2 (Lima, 1920), pp. 264-279 y 401-419.

Cuadro 2. Población residente en obrajes del corregimiento de Conchucos según filiación étnica en 1774

\begin{tabular}{lccccc}
\hline \multicolumn{1}{c}{ Parroquia } & Espańoles & Mestizos & Indios & $\begin{array}{c}\text { Total de población } \\
\text { en obrajes }\end{array}$ & $\begin{array}{c}\text { Total en } \\
\text { parroquias }\end{array}$ \\
\hline Pomabamba & -- & 84 & 239 & 323 & 2542 \\
Piscobamba & -- & 45 & 405 & 450 & 5475 \\
San Luis & 4 & -- & 168 & 172 & 3859 \\
Santo Domingo de Huari del Rey & -- & -- & 235 & 235 & 2295 \\
San Marcos & -- & -- & 42 & 42 & 1818 \\
Total en obrajes & $\mathbf{4}$ & $\mathbf{1 2 9}$ & $\mathbf{1 0 8 9}$ & $\mathbf{1 2 2 2}$ & 15989 \\
\hline Total & 2074 & 16422 & 19351 & 38115 & \\
\hline Porcentaje sobre el total & $\mathbf{0 , 2}$ & $\mathbf{0 , 7 8}$ & $\mathbf{5 , 6}$ & 3,2 & \\
\hline
\end{tabular}

Fuente: Elaborado por la autora con datos de AAL, Visitas, leg., 5, exp. 5, 10, 13, 18. 
Cuadro 3. Población residente en obrajes de las parroquias del corregimiento de Conchucos de 1774

\begin{tabular}{lccccc}
\hline \multicolumn{1}{c}{ Parroquia } & $\begin{array}{c}\text { Residentes } \\
\text { en obrajes }\end{array}$ & $\begin{array}{c}\text { Residentes } \\
\text { en pueblos }\end{array}$ & $\begin{array}{c}\text { Residentes } \\
\text { en haciendas } \\
\text { y estancias }\end{array}$ & Total & $\begin{array}{c}\text { Porcentaje } \\
\text { en obrajes }\end{array}$ \\
\hline Pomabamba & 323 & 1135 & 1084 & 2542 & 12.7 \\
Piscobamba & 450 & 1667 & 3358 & 5475 & 8.2 \\
San Luis & 172 & 1333 & 2354 & 3859 & 4.4 \\
Santo Domingo de Huari del Rey (Huari) & 235 & 1041 & 1019 & 2295 & 10.2 \\
San Marcos & 42 & 235 & 1541 & 1818 & 2.3 \\
Total en estas parroquias & 1222 & 5411 & 9356 & 15989 & 7,64 \\
Total en Conchucos & 1222 & 20035 & 16858 & 38115 & 3.2 \\
\hline
\end{tabular}

* Incluye el asiento minero de Atun-Conchucos con 957 individuos.

Fuente: Elaborado por la autora con datos de AAL, Visitas, leg. 5, exp. 5, 10, 13, 18.

Cuadro 4. Porcentaje de población residente en obrajes, pueblos y asentamientos del corregimiento de Conchucos en 1774

\begin{tabular}{lccc}
\hline \multicolumn{1}{c}{ Parroquia } & Obrajes & Pueblos & Haciendas y otros \\
\hline Pallasca & 0 & 52,99 & 47,0 \\
Cabana & 0 & 100 & 0 \\
Tauca & 0 & 100 & 0 \\
Llapo & 0 & 100 & 0 \\
Corongo & 0 & 34,62 & 65,37 \\
Sihuas & 0 & 49,61 & 50,38 \\
Piscobamba & 8,21 & 30,44 & 61,33 \\
Pomabamba & 12,7 & 44,64 & 42,64 \\
Chacas & 0 & 55,59 & 44,41 \\
San Luis & 4,46 & 34,54 & 61 \\
Chavín & 0 & 63,51 & 36,49 \\
Huari & 10,24 & 45,36 & 44,4 \\
Llamellín & 0 & 37,77 & 62,22 \\
Uco & 0 & 43,04 & 56,96 \\
San Marcos & 2,3 & 12,92 & 84,76 \\
\hline Total & 3,2 & 50,05 & 44,23 \\
\hline
\end{tabular}

Fuente: Elaborado por la autora con datos de datos de AAL, Visitas, leg. 4, exp. 13, 15, 23, 25; leg. 5, expds. 1,3, 5, 10, 12, 13, 15, 17, 18, 24. 
Cuadro 5. Personas con profesión textil en distritos y provincias del antiguo corregimiento de Conchucos, 1876

\begin{tabular}{|c|c|c|c|c|c|c|c|c|c|c|c|}
\hline Distrito & A & B & $\mathrm{C}$ & $\mathrm{D}$ & $\mathrm{E}$ & $\mathrm{F}$ & G & $\mathrm{H}$ & I & $\mathrm{J}$ & K \\
\hline Pallasca & 0 & 171 & 11 & 0 & 0 & 0 & 182 & 16,5 & 920 & 1102 & 7285 \\
\hline Llapo & 0 & 19 & 0 & 5 & 2 & 0 & 26 & 23,4 & 85 & 111 & 2491 \\
\hline Corongo & 0 & 0 & 0 & 0 & 0 & 0 & 0 & 0 & 184 & 184 & 5981 \\
\hline Cabana & 0 & 254 & 5 & 5 & 0 & 2 & 266 & 26,8 & 723 & 989 & 3727 \\
\hline Tauca & 0 & 0 & 0 & 0 & 0 & 0 & 0 & 0 & 577 & 577 & 3141 \\
\hline Provincia de Pallasca & 0 & 444 & 16 & 10 & 2 & 2 & 474 & 15,9 & 2480 & 2963 & 22625 \\
\hline Pomabamba & 2 & 199 & 22 & 0 & 6 & 7 & 236 & 9,1 & 2336 & 2572 & 10119 \\
\hline Piscobamba & 0 & 106 & 52 & 1 & 18 & 2 & 179 & 4,3 & 3935 & 4114 & 15355 \\
\hline Parobamba & 0 & 0 & 35 & 0 & 0 & 0 & 35 & 1,8 & 1847 & 1882 & 7860 \\
\hline Sihuas & 0 & 13 & 6 & 0 & 2 & 0 & 21 & 0,9 & 2114 & 2135 & 9607 \\
\hline Provincia de Pomabamba & 2 & 318 & 95 & 1 & 26 & 9 & 471 & 4,4 & 10232 & 10703 & 42941 \\
\hline Llamellín & 4 & 1668 & 6 & 0 & 0 & 1 & 1679 & 98,4 & 2020 & 1699 & 7564 \\
\hline Huari & 7 & 1573 & 36 & 10 & 7 & 6 & 1639 & 38,9 & 2678 & 4317 & 9429 \\
\hline Huantar & 0 & 768 & 12 & 0 & 7 & 0 & 787 & 49,9 & 788 & 1575 & 3599 \\
\hline Huachis & 0 & 1499 & 16 & 8 & 4 & 5 & 1532 & 45,5 & 1838 & 3370 & 6659 \\
\hline Chavín & 7 & 639 & 29 & 1 & 2 & 7 & 685 & 46,6 & 785 & 1470 & 3223 \\
\hline Chacas & 10 & 1865 & 72 & 0 & 3 & 7 & 1957 & 39,1 & 3050 & 5007 & 12914 \\
\hline Uco & 0 & 1127 & 64 & 0 & 4 & 4 & 1199 & 52,4 & 1086 & 2285 & 5015 \\
\hline San Marcos & 0 & 336 & 19 & 1 & 2 & 0 & 358 & 40,5 & 526 & 884 & 3351 \\
\hline San Luis & 0 & 922 & 33 & 1 & 0 & 1 & 957 & 30,4 & 2193 & 3150 & 8012 \\
\hline Provincia de Huari & 28 & 10397 & 259 & 49 & 29 & 31 & 10793 & 41,9 & 14964 & 25757 & 59766 \\
\hline Total & 30 & 11159 & 370 & 60 & 57 & 42 & 11738 & 29,7 & 17676 & 39423 & 125332 \\
\hline
\end{tabular}

Fuente: Elaborado por la autora con datos de Censo General de la república del Perú formado en 1876, Lima: Imprenta del Teatro, 1878, vol. 1.

Clave: $\mathrm{A}=$ Hilanderos, $\mathrm{B}=$ Hilanderas, $\mathrm{C}=$ Tejedores, $\mathrm{D}=$ Tejedoras, $\mathrm{E}=$ Tintoreros, $\mathrm{F}=$ Tintoreras, $\mathrm{G}=$ Total de personas con profesión en textilería, $\mathrm{H}=$ Porcentaje de personas con profesión textil sobre el total de personas con profesión, $\mathrm{I}=$ Total de personas con profesión no vinculada a la textilería, $\mathrm{J}=$ Total de personas que declaran una profesión, $\mathrm{K}$ = Total de población. 
Cuadro 6. Hombres y mujeres que declaran una profesión del ramo textil y que declaran alguna profesión en general en distritos y provincias del antiguo corregimiento de Conchucos, 1876

\begin{tabular}{|c|c|c|c|c|c|c|c|c|}
\hline Distrito & A & B & $\mathrm{C}$ & $\mathrm{D}$ & $\mathrm{E}$ & $\mathrm{F}$ & G & $\mathrm{H}$ \\
\hline Pallasca & 11 & 171 & 182 & 93,9 & 896 & 206 & 1102 & 18,6 \\
\hline Llapo & 2 & 24 & 26 & 92,3 & 60 & 51 & 111 & 45,9 \\
\hline Corongo & 0 & 0 & 0 & 0 & 176 & 8 & 184 & 4,3 \\
\hline Cabana & 5 & 261 & 266 & 98,1 & 627 & 362 & 989 & 36,6 \\
\hline Tauca & 0 & 0 & 0 & 0 & 540 & 37 & 577 & 6,4 \\
\hline Provincia de Pallasca & 18 & 456 & 474 & 96,2 & 2299 & 664 & 2963 & 24,6 \\
\hline Pomabamba & 30 & 206 & 236 & 87,2 & 2261 & 311 & 2572 & 12,1 \\
\hline Piscobamba & 70 & 109 & 179 & 60,9 & 3710 & 404 & 4114 & 9,8 \\
\hline Parobamba & 35 & 0 & 35 & 0 & 1795 & 87 & 1882 & 4,6 \\
\hline Sihuas & 8 & 13 & 21 & 61,9 & 2078 & 57 & 2135 & 2,6 \\
\hline Provincia de Pomabamba & 143 & 328 & 471 & 69,6 & 9844 & 859 & 10703 & 8 \\
\hline Llamellín & 10 & 1669 & 1679 & 99,4 & 1821 & 1878 & 3699 & 50,8 \\
\hline Huari & 50 & 1589 & 1639 & 96,9 & 2216 & 2101 & 4317 & 48,6 \\
\hline Huantar & 19 & 768 & 787 & 97,5 & 750 & 825 & 1575 & 52,3 \\
\hline Huachis & 20 & 1512 & 1532 & 98,7 & 1744 & 1626 & 3370 & 48,2 \\
\hline Chavín & 38 & 647 & 685 & 94,4 & 680 & 790 & 1470 & 53,7 \\
\hline Chacas & 85 & 1872 & 1957 & 95,6 & 2633 & 2374 & 5007 & 47,4 \\
\hline Uco & 68 & 1131 & 1199 & 94,3 & 1046 & 1239 & 2285 & 54,2 \\
\hline San Marcos & 21 & 337 & 358 & 94,1 & 502 & 382 & 884 & 43,2 \\
\hline San Luis & 33 & 924 & 957 & 96,5 & 1950 & 1200 & 3150 & 38,1 \\
\hline Provincia de Huari & 344 & 10449 & 10793 & 96,8 & 13341 & 12416 & 25757 & 48,2 \\
\hline Total & 505 & 11233 & 11738 & 95,7 & 25484 & 13939 & 39423 & 35,35 \\
\hline
\end{tabular}

Fuente: Elaborado por la autora con datos de Censo General de la república del Perú formado en 1876, Lima: Imprenta del Teatro, 1878, vol. 1.

Clave: $\mathrm{A}=$ Hombres con profesión textil; $\mathrm{B}=$ Mujeres con profesión textil; $\mathrm{C}=$ Total de personas con profesión textil; $\mathrm{D}=$ porcentaje de mujeres con profesión textil sobre el total; $\mathrm{E}=$ hombres con profesión; $\mathrm{F}=$ mujeres con profesión; $\mathrm{G}=$ total de personas con profesión; $\mathrm{H}$ = porcentaje de mujeres con profesión. 


\section{REFERENCIAS BIBLIOGRÁFICAS}

\section{Fuentes primarias}

Archivo General de la Nación (AGN)

Archivo Arzobispal de Lima (AAL)

Censo General de la república del Perú formado en 1876. Lima: Imprenta del Teatro, 1878,

\section{Fuentes secundarias}

Brines Tyrer, R. (1988). Historia demográfica y económica de la Audiencia de Quito: población indigena e industria textil, 1600-1800, Quito: Banco Central del Ecuador.

Carrillo y Ariza, Manuel (1994). Ancash. En Miguel Pinto y Alejandro Salinas (comps.), Geografía de la Sierra, siglo XIX. Ancash. Lima: Universidad Nacional Mayor de San Marcos.

Chocano, M. (2006). La evolución de la población y los nuevos perfiles demográficos de una región andina: Conchucos, 1543-1940. Revista Andina, 42, 129-160.

Escandell Tur, N. (1997). Producción y comercio de tejidos coloniales: los obrajes y chorrillos del Cusco, 1570-1820. Lima: Centro Bartolomé de las Casas.

Middendorf, E. W. (1973). El Perú: observaciones y estudios del pais y sus habitantes durante una permanencia de 25 años. Lima: Universidad Nacional Mayor de San Marcos, Dirección Universitaria de Biblioteca y Publicaciones, 2 vols., vol. 1.

Miño Grijalva, M. (1993). La manufactura colonial: aspectos comparativos entre el obraje andino y el novohispano. En Heraclio Bonilla, El sistema colonial en la América española (pp. 102-153). Barcelona: Crítica.

Mogrovejo, T. (1920). Libro de visitas. Visita de 1593. Revista del Archivo Nacional, tomo 1 y 2.

Salas, M. (1998). Estructura colonial del poder español en el Perú. Huamanga (Ayacucho) a través de sus obrajes, siglos XVI-XVIII, 3 vols. Lima: Fondo Editorial de la Pontificia Universidad Católica.

Silva Santisteban, F. (1964). Los obrajes en el virreinato del Perú. Lima: Museo Nacional de Historia.

Wiener, Ch. (1880). Pérou et Bolivie. Récit de voyage suivi d'études archéologiques et ethnographiques et des notes sur l'écriture et les langues des populations indiennes, París: Libraire Hachette.

Documento recibido el 3 de marzo de 2016

y aprobado el 16 de mayo de 2016 